\title{
Pregnancy outcome in Non-cirrhotic portal hypertension
}

\author{
Sandya M. R.*, Manjula S. K., Sr. Ancy \\ Department of Obstetrics and Gynecology, St John's Medical College, Karnataka, India
}

Received: 01 August 2017

Accepted: 01 September 2017

\section{*Correspondence:}

Dr. Sandya M. R.,

E-mail: drsamskruthii@gmail.com

Copyright: $\odot$ the author(s), publisher and licensee Medip Academy. This is an open-access article distributed under the terms of the Creative Commons Attribution Non-Commercial License, which permits unrestricted non-commercial use, distribution, and reproduction in any medium, provided the original work is properly cited.

\section{ABSTRACT}

Background: To study the maternal and fetal outcome of non-cirrhotic portal hypertension (NCPH) in pregnancy.

Methods: We retrospectively analyzed ten women with the diagnosis of NCPH in pregnancy. The study was done at St John's Medical College Hospital Bangalore, Karnataka from January 2012 - January 2016. All the necessary data was obtained by record review.

Results: The mean age of the pregnant woman was 25.5 years. Among 10 women with the diagnosis of NCPH 4 had Non-cirrhotic portal fibrosis (NCPF) and 6 had Extrahepatic portal venous obstruction (EHPVO). Six patients were diagnosed with NCPH prior to pregnancy; while among the remaining 4 patients, 1 had variceal bleed and the other 3 manifested with splenomegaly during pregnancy which led to the diagnosis of $\mathrm{NCPH}$. All these 4 patients were successfully managed with beta blockers alone without any surgical intervention during pregnancy. Thrombocytopenia and splenomegaly were the most common clinical manifestations which were observed in all 10 patients. Severe thrombocytopenia (platelet $<50,000$ cells $/ \mathrm{mm}^{3}$ ) was seen in 7 patients who received platelet transfusion. Six $(60 \%)$ of patients had vaginal delivery, the other 4 underwent cesarean section due to meconium stained liquor and fetal distress in early labor. Hence cesarean delivery was reserved only for obstetric indication. Postpartum hemorrhage was seen in 2 patients managed conservatively, one patient on $3^{\text {rd }}$ postoperative day developed ascites and pleural effusion requiring pleural tapping and diuretics with successful recovery. There was no maternal mortality during the study period. The fetal/neonatal outcome was good in the present study with $90 \%$ of babies with good APGAR score, whereas 1 preterm neonate developed HIE stage 2 requiring prolonged NICU stay. The overall pregnancy outcome was good in the present study.

Conclusions: Pregnancies can be allowed and managed successfully in patients with NCPH.

Keywords: Extrahepatic portal venous obstruction, Non-cirrhotic portal hypertension, Non-cirrhotic portal fibrosis, Pregnancy outcome

\section{INTRODUCTION}

Portal hypertension is characterized by an increase in portal pressure $(>10 \mathrm{mmHg})$ due to cirrhosis of the liver or of non-cirrhotic disease. ${ }^{1}$ Non-cirrhotic portal hypertension $(\mathrm{NCPH})$ comprises diseases having an increase in portal pressure secondary to intrahepatic or prehepatic lesions, in the absence of cirrhosis. ${ }^{2} \mathrm{NCPH}$ accounts for $30 \%$ of the variceal bleeding. ${ }^{2}$ Two most common causes of NCPH are non-cirrhotic portal fibrosis
(NCPF) and extrahepatic portal venous obstruction (EHPVO).

NCPF is a syndrome of unknown etiology, characterized by obliterative portovenopathy leading to portal hypertension, massive splenomegaly and variceal bleed, with preserved liver function. ${ }^{2}$ EHPVO is obstruction of the extrahepatic portal vein with or without the involvement of the intrahepatic portal veins, may even involve splenic or superior mesenteric veins. ${ }^{3}$ Pregnancy 
is a potential hazard for occurrence of recurrent variceal bleed due to increased blood volume and cardiac output increasing the portal flow, which increases flow in the collaterals and also aggravates portal hypertension. ${ }^{4}$ Management of portal hypertension thus requires knowledge of effects of pregnancy on portal hemodynamics and effects of portal hypertension on maternal and fetal outcome. We report our experience of $\mathrm{NCPH}$ in ten patients.

\section{METHODS}

We analyzed 10 patients with the diagnosis of noncirrhotic portal hypertension (NCPH), who were managed at the Department of obstetrics and gynecology at St John's medical college hospital. Study design: It was a retrospective observational study. Study duration: The study was conducted during the years January 2012 January 2016.

\section{Inclusion criteria}

Pregnant women diagnosed with NCPH prior to pregnancy or in the current pregnancy during the study period were included in the study.

\section{Exclusion criteria}

Women with the diagnosis of portal hypertension secondary to liver cirrhosis were excluded from the study.

The diagnosis was mainly by patient symptomatology and on the basis of ultrasonography with Doppler (showing portal cavernoma, portal vein fibrosis), the size of liver and by the presence of features of portal hypertension like splenomegaly, ascites and endoscopic evidence of varices. Patients with liver cirrhosis, parenchymal liver disease were excluded from the study. The demographic details, clinical presentation, symptomatology, diagnosis during or prior to pregnancy, treatment received, antepartum and postpartum complications, fetal outcome were analyzed in the present study. These women were managed by joint supervision of obstetricians and gastroenterologists.

\section{RESULTS}

A total of 10 patients with NCPH (6-EHPVO, 4-NCPF) were analyzed. The mean age of the women in the present study was 25.5 years. Four patients were diagnosed during current pregnancy, one of them presented with variceal bleed and other 3 had splenomegaly. The other 6 patients were diagnosed with NCPH prior to pregnancy. Majority of the patients were primigravida $6(60 \%)$. The mean gestational age at delivery was 38 weeks and the mean birth weight was $2.7 \mathrm{Kg}$ in the present study (Table 1). Variceal bleed and splenomegaly were the most common manifestation at the time of diagnosis accounting for $50 \%$ of the cases. The other included thrombocytopenia, anemia and a case of ascites and pleural effusion required pleural tapping and diuretics (Table 2).

Table 1: Demographic characteristics.

\begin{tabular}{|ll|}
\hline Characteristic & Number $(\%) n=10$ \\
\hline Mean age & 25.5 years \\
\hline Mean gestational age & 38 weeks \\
\hline Parity & $6(60)$ \\
\hline Primigravida & $4(40)$ \\
\hline $\begin{array}{l}\text { Multigravida } \\
\text { Cases diagnosed during } \\
\text { pregnancy }\end{array}$ & $4(40)$ \\
\hline Mean birth weight & $2.7 \mathrm{Kg}$ \\
\hline
\end{tabular}

Table 2: Clinical manifestation at diagnosis.

\begin{tabular}{|ll|}
\hline Clinical manifestation & Number $(\%) n=10 *$ \\
\hline Variceal bleed & $5(50)$ \\
\hline Splenomegaly & $4(40)$ \\
\hline Thrombocytopenia & $2(20)$ \\
\hline Anemia & $3(30)$ \\
\hline Pain abdomen & $1(10)$ \\
$\begin{array}{l}\text { *Number does not correlate as same patient more than one } \\
\text { clinical manifestation }\end{array}$
\end{tabular}

Thrombocytopenia was the most common complication and was seen in all patients. Severe thrombocytopenia (platelet $<50,000$ cells/mm3) was seen in 7 patients who received platelet transfusion. Anemia was the next common complication seen in 9 patients, 4 patients had $\mathrm{Hb}<7 \mathrm{~g} / \mathrm{dl}$ and were transfused with packed cells.

Obstetric complications preterm labor and preeclampsia was seen in one patient each. Four patients underwent cesarean section due to fetal distress and meconium stained liquor in early labor (Table 3 ).

Table 3: Complications during pregnancy.

\begin{tabular}{|ll|}
\hline Complication & Number $(\%) n=10 *$ \\
\hline Splenomegaly & $10(100)$ \\
\hline Thrombocytopenia & $10(100)$ \\
\hline Anemia & $9(90)$ \\
\hline Variceal bleed & $1(10)$ \\
\hline Mild preeclampsia & $1(10)$ \\
\hline Preterm labour & $1(10)$ \\
\hline *Number does not correlate as same patient had more than one \\
complication
\end{tabular}

Three patients had complication in the postpartum period 2 had postpartum hemorrhage requiring blood transfusion, 1 patient had ascites and pleural effusion in the postnatal period, she required pleural tapping and diuretics (Table 4).

Among neonatal complications Respiratory distress syndrome (RDS) and Low birth weight (LBW) were the most common complication seen in 4 neonates. One baby 
had hyperbilirubinemia and the other had stage 2 Hypoxic ischemic encephalopathy (HIE) requiring prolonged stay in NICU. Ninety percent of the babies had good APGAR (mean $8 / 10$ at $1^{\prime}$ and $9 / 10$ at 5 ' respectively) at birth except for one preterm neonate with APGAR of (3/10 at 1 ' and $6 / 10$ at 5 ' respectively, which later was diagnosed with HIE stage 2 (Table 5). RDS and LBW were the most common complications seen in 4 and 3 neonates respectively.

Table 4: Complications during postnatal period.

\begin{tabular}{|ll|}
\hline Complication & Number $(\%) \mathrm{n}=\mathbf{1 0}$ \\
\hline Postpartum hemorrhage & $2(20)$ \\
\hline Ascites + Pleural effusion & $1(10)$ \\
\hline No complication & $7(70)$ \\
\hline
\end{tabular}

Table 5: Fetal/Neonatal outcome.

\begin{tabular}{|ll|}
\hline Fetal/Neonatal complications & Number $(\%) \mathbf{n = 1 0}$ \\
\hline Meconium stained liquor & $4(40)$ \\
\hline RDS & $4(40)$ \\
\hline Low birth weight & $3(30)$ \\
\hline Hyperbilirubinemia & $2(20)$ \\
\hline TTN & $1(10)$ \\
\hline HIE & $1(10)$ \\
\hline $\begin{array}{l}\text { Number does not correlate as the same neonate had more than } \\
\text { one complication. }\end{array}$
\end{tabular}

\section{DISCUSSION}

Pregnancy with portal hypertension is an uncommon entity. The advance in medical treatment has helped the patients with Extra hepatic portal venous obstruction (EHPVO) and Non-cirrhotic portal fibrosis (NCPF) to survive till the adult life. Maternal prognosis in EHPVO and NCPF is better than in liver cirrhosis. NCPH is the most common cause of portal hypertension in developing countries. ${ }^{1}$ The prognosis of this disease is better than cirrhosis of liver. The increased blood volume and cardiac output in pregnancy increases the portal venous flow and aggravates portal hypertension and its complications. $^{2}$ Patients with NCPH present with upper gastrointestinal bleed, ascites, splenomegaly, jaundice and growth restriction. Other squeal includes hyper dynamic circulation, pulmonary complications and portosystemic encephalopathy secondary to increased portosystemic collateral circulation. Prenatal obliteration of varices by either endoscopic variceal ligation (EVL) or endoscopic sclerotherapy (EST) reduces the risk of complications and certainly improves the pregnancy and perinatal outcome. ${ }^{1,4}$

In the present study, the clinical manifestation, pregnancy and perinatal outcome were analyzed.

Of the ten patients with NCPH studied during Jan 2012 to Jan 2016 4(40\%) had NCPF and 6(60\%) had EHPVO. Fertility is generally unaffected in NCPH unlike in women with cirrhosis. ${ }^{5} \mathrm{NCPH}$ can have varied clinical presentation like upper gastrointestinal bleeding, hypersplenism, jaundice, ascites. The incidence of hematemesis in patients with EHPVO and NCPF is approximately $7 \% .{ }^{6}$ In the present study 5 patients presented with variceal bleed and 4 of them also had splenomegaly at the time of diagnosis. Four out of five patients underwent surgical treatment (3-EST, 1-EVL) prior to pregnancy, none of these patients had variceal bleed during their pregnancy. Four patients diagnosed with NCPH during current pregnancy 1 manifested with variceal bleed and 3 of them had splenomegaly all were successfully managed medically with beta blockers. There was no surgical intervention during pregnancy in the present study. The observation in the present study was in accordance with the study by Mandal et $\mathrm{al}^{7}$ wherein patients with prenatal obliteration of varices did not manifest with recurrent bleed during pregnancy. Thrombocytopenia secondary to splenomegaly is one of the major complications of NCPH. Aggarwal et $\mathrm{al}^{8}$ reported $50 \%$ of their patients received platelet transfusion intrapartum. In the present study thrombocytopenia (platelet $<1$ lakh cells $/ \mathrm{mm}^{3}$ ) was seen in all 10 patients, $7 / 10$ patients had severe thrombocytopenia (platelet $<50,000$ cells $/ \mathrm{mm}^{3}$ ) received platelet transfusion 1 during antenatal period and 6 during intrapartum period. Anemia was the next common complication and $4 / 10$ patients with $\mathrm{Hb}<7 \mathrm{~g} / \mathrm{dl}$ received transfusion. The obstetric outcome of our patients was similar to other studies., ${ }^{2,4}$ Mild preeclampsia and preterm labour were among the obstetric complications seen in 1 patient each. Cesarean delivery was reserved for obstetric indication. We report one patient who had ascites and massive pleural effusion in the postpartum period on $3^{\text {rd }}$ day following delivery she required pleural tapping and diuretics. She completely recovered and was discharged stable. Meconium stained liquor was the most common fetal/neonatal complication seen in $40 \%$ of babies, next to follow was low birth weight and hyperbilirubinemia seen in $30 \%$ and $20 \%$ respectively. One preterm baby had low APGAR score at birth was diagnosed with HIE stage 2 and required prolonged NICU stay and is on regular follow up. There was no maternal or perinatal mortality in the present study.

Most of the available guidelines in the literature are pertaining to the management of pregnancy with portal hypertension in liver cirrhosis. The present study describes pregnancy outcome in patients with noncirrhotic portal hypertension. The risk of variceal bleed may be increased during pregnancy in patients with noncirrhotic portal hypertension, pregnancy can still be allowed and managed successfully under close supervision of obstetricians and gastroenterologists specialized in endoscopic variceal ligation and sclerotherapy. ${ }^{10}$ Management of portal hypertension in pregnancy is similar to non-pregnant state. Beta blockers are used to reduce the portal venous pressures. Surgical interventions like Endoscopic sclerotherapy and Endoscopic variceal ligation or banding, shunt surgery can be successfully performed during pregnancy in the 
second trimester. ${ }^{11}$ However, there was no surgical intervention in the present study.

\section{CONCLUSION}

In conclusion, we found that variceal bleed is the most common clinical manifestation in NCPH. Prenatal correction of high risk varices has good pregnancy outcome. Platelet transfusion is required intrapartum when the count $<50,000$ cells $/ \mathrm{mm} 3$. Cesarean delivery should be reserved only for obstetric indications. Pregnancies can be allowed and managed successfully in patients with NCPH. With multidisciplinary approach in a tertiary centre involving specialists from medical gastroenterologist, hematologist, anesthetist, neonatologist apart from senior obstetrician's results in favorable maternal and fetal outcome.

\section{ACKNOWLEDGMENTS}

Authors would like to thank Dr. Shirley George, Professor and HOD, Department of Obstetrics and Gynecology St John's Medical College for the necessary support.

Funding: No funding sources

Conflict of interest: None declared

Ethical approval: The study was approved by the Institutional Ethics Committee

\section{REFERENCES}

1. Rajekar H, Vasishta RK, Chawla YK, Dhiman RK. Noncirrhotic portal hypertension. J Clin Exp Hepatol. 2011;1(2):94-108.

2. Sarin SK, Kapoor D. Non-cirrhotic portal fibrosis: current concepts and management. J Gastroenterol Hepatol. 2002;17(5):526-34.
3. De Franchis R, Faculty Baveno V. Revising consensus in portal hypertension: report of the Baveno $\mathrm{V}$ consensus workshop on methodology of diagnosis and therapy in portal hypertension. J Hepatol. 2010;53:762-8.

4. Aggarwal N, Sawhney H, Vasishta K, Dhiman RK, Chawla Y. Non-cirrhotic portal hypertension in pregnancy. Int J Gynaecol Obstet. 2001;72:1-7.

5. Dilwari JB, Chawla YK. Extrahepatic portal venous obstruction. Gut. 1998;29:554-5.

6. Sandhu GS, Vardhan S, Das S. Pregnancy with portal hypertension. Case report. The J of Obstet Gynecol India. 2007;57(3):261-2.

7. Mandal D, Dattaray C, Sarkar R, Mandal S, Choudhary A, Maity TK. Is pregnancy safe with extrahepatic portal vein obstruction? AN analysis. Singapore Med J/ 2012;53:676-80.

8. Aggarwal N, Chopra S, Raveendran A, Suri V, Dhiman RK, Chawla YK. Extrahepatic portal vein obstruction and pregnancy outcome: largest reported experience. J Obstet Gynaecol Res. 2011;37:575-80.

9. Sumana G, Dadhwal V, Deka D, Mittal S. Noncirrhotic portal hypertension and pregnancy outcome. J Obstet Gynaecol Res. 2008;34:801-4.

10. Aggarwal N, Negi N, Aggarwal A, Bodh V, Dhiman RK. Pregnancy with Portal Hypertension. J Clin Exp Hepatol. 2014;4(2):163-71.

11. Nambisan B, Radha SK, Brahmanandan M, Kanakamma LG. A case of extra hepatic portal vein obstruction in pregnancy with superimposed preeclampsia. Int J Reprod Contracept Obstet Gynecol. 2016;5:3213-5.

Cite this article as: Sandya MR, Manjula SK, $\mathrm{Sr}$ Ancy. Pregnancy outcome in Non-cirrhotic portal hypertension. Int J Reprod Contracept Obstet Gynecol 2017;6:4534-7. 